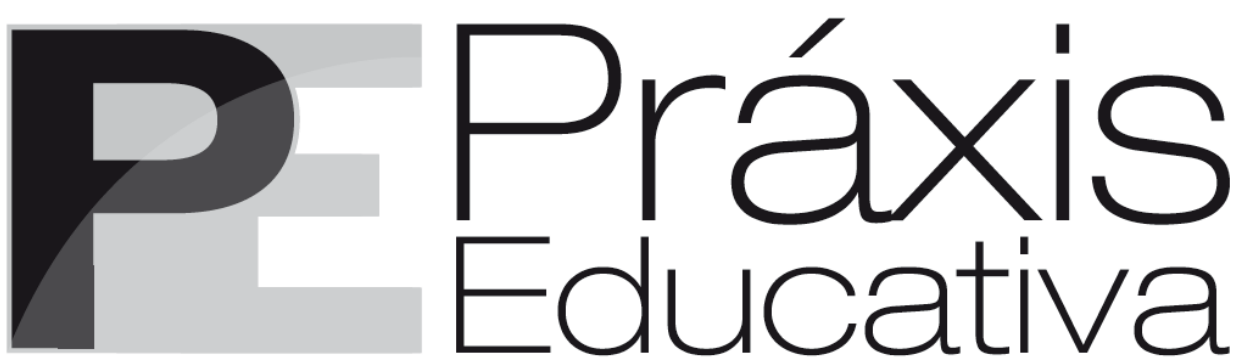

ISSN 1809-4031

elSSN 1809-4309

http://dx.doi.org/10.5212/PraxEduc.v.14n3.014

\title{
Condição adolescente e socialização política nas ocupações secundaristas em Caxias do Sul, RS
}

\section{Adolescent condition and political socialization in High School occupation in Caxias do Sul, RS}

\author{
Condición adolescente y socialización política \\ en las tomas secundaristas en Caxias do Sul, RS
}

\author{
Scarlett Giovana Borges* \\ Rodrigo Manoel Dias da Silva**
}

\begin{abstract}
Resumo: Este artigo tem como temática as ocupações das escolas públicas no ano de 2016 em Caxias do Sul, Rio Grande do Sul. O objetivo é discutir a influência da condição adolescente na socialização política das ocupações. As fontes da pesquisa são analisadas de maneira qualitativa, utilizando como referencial os termos "experiência", discutido por Edward Thompson (1981), e "condição adolescente", apresentado por Martuccelli (2016). Por meio desse arcabouço teórico-metodológico, reflete-se que a condição adolescente é um fator de relevante influência na experiência política do movimento, que gerou empecilhos para o desenvolvimento das ocupações, assim como serviu de base para o processo de aprendizagem política das e dos estudantes. Nesse sentido, conclui-se que as ocupações foram potentes para a transformação subjetiva das e dos "ocupas", modificando a sua experiência de escolarização e seu entendimento acerca da política de educação.

Palavras-chave: Ocupações Estudantis. Condição adolescente. Movimento estudantil.
\end{abstract}

Abstract: This paper is about the occupations of public schools in the year 2016 in Caxias do Sul, Rio Grande do Sul, Brazil. The aim is to discuss the influence of the adolescent condition on the political socialization of the occupations. The sources of the research are analysed qualitatively, using as reference the terms "experience", discussed by Edward Thompson (1981), and "adolescent condition", presented by Martuccelli (2016). Through this theoretical-methodological outline, it is reflected that the adolescent condition is a factor of relevant influence in the political experience of the movement, which generated obstacles to the development of occupations, as well as it served as a basis for the students' political learning process. In this sense, it is concluded that the occupations were potent for the students' subjective transformation, changing their schooling experience and their understanding of education policy.

Keywords: Student occupation. Adolescent condition. Student movement.

\footnotetext{
* Doutoranda do Programa de Pós-Graduação em Educação da Universidade do Vale do Rio dos Sinos (UNISINOS). Bolsista da Coordenação de Aperfeiçoamento de Pessoal de Nível Superior (CAPES). E-mail: <scarlettgborges@hotmail.com>.ORCID: https://orcid.org/0000-0001-7733-5245

** Professor da Universidade do Vale do Rio dos Sinos (UNISINOS). Doutor em Ciências Sociais pela Universidade do Vale do Rio dos Sinos (UNISINOS). E-mail: <rodrigoddsilva@hotmail.com>. ORCID: https://orcid.org/00000001-8501-5903
}

Práxis Educativa, Ponta Grossa, v. 14, n. 3, p. 1049-1065, set./dez. 2019 Disponível em: < http://www.revistas2.uepg.br/index.php/praxiseducativa> 
Resumen: Este artículo tiene como temática las tomas de las escuelas públicas en el año 2016 en Caxias do Sul, Rio Grande do Sul, Brasil. El objetivo es discutir la influencia de la condición adolescente en la socialización política de las ocupaciones. Las fuentes de la investigación son analizadas de manera cualitativa, utilizando como referencial los términos "experiencia", discutido por Edward Thompson (1981), y "condición adolescente", presentado por Martuccelli (2016). Por medio de este marco teóricometodológico, se reflexiona sobre la condición adolescente ser un factor de relevante influencia en la experiencia política del movimiento, que generó impedimentos para el desarrollo de las tomas, como también sirvió de base para el proceso de aprendizaje político de las y de los estudiantes. En ese sentido, se concluye que las tomas fueron potentes para la transformación subjetiva de las y de los "ocupas" (quienes realizan las tomas), modificando su experiencia de escolarización y su entendimiento acerca de la política de educación.

Palabras claves: Tomas Estudiantiles. Condición adolescente. Movimiento estudiantil.

\section{Movimento secundarista de ocupações}

O movimento de ocupação das escolas públicas, pelas e pelos estudantes da educação básica, entre 2015 e 2016, no Brasil, foi uma experiência de complexa dimensão social e política. Ainda que a ocupação como tática de luta seja uma ação comum em alguns movimentos sociais com décadas de organização, tal evento engendrou a emergência de sujeitos pouco vistos ou com pouco espaço de visibilidade em nosso cenário político contemporâneo, a saber: as e os estudantes secundaristas. Embora a expressão política de ocupar seja menos usual no movimento estudantil do que outras formas de protesto, concordamos com Groppo et al. (2017) quando afirmam que as ocupações secundaristas não surgiram de maneira espontânea, mas como resultado do acúmulo das vivências políticas juvenis e do conhecimento intergeracionais dos movimentos sociais.

A pesquisa aqui apresentada teve como foco o cotidiano das ocupações em Caxias do Sul, município com o segundo maior número de habitantes do Rio Grande do Sul. Na cidade, foram ocupadas quatro escolas, durante o período de maio e junho de 2016. Em comum a outras ocupações realizadas na rede estadual de ensino em municípios do Rio Grande do Sul, as e os estudantes de Caxias do Sul indicam como motivação do movimento as péssimas condições físicas das escolas e as precárias condições de trabalho das e dos profissionais da educação, elementos que descreditam a qualidade da educação ofertada pelo Estado.

Do ponto de vista metodológico, o estudo foi produzido a partir da observação e do registro das experiências vividas nas ocupações. Em específico, foram realizadas visitas de campo às escolas ocupadas, acompanhamento do desenrolar do movimento via redes sociais virtuais, coleta de materiais diversificados (postagens escritas, fotos e vídeos), arquivo de reportagens dos veículos de comunicação independentes e oficiais, bem como as notas emitidas no site da Secretaria da Educação do Rio Grande do Sul (SEDUC-RS). Após a desocupação, realizamos quatro entrevistas semiestruturadas com uma ou um estudante de cada ocupação. Esses materiais foram analisados de maneira qualitativa, sob o ponto de vista do materialismo histórico dialético da experiência cotidiana formulada por Edward Thompson (1981). Escrutinamos também as fontes, buscando compreender o que a experiência de ocupação apresenta acerca da condição adolescente, principalmente em relação à cidadania escolar (MARTUCCELLI, 2016).

Ao atentarmos para a temática das ocupações, percebemos a necessidade da discussão social de questões fundamentais para a Política de Educação. As e os estudantes apontam as limitações de sua participação e escuta do seu ponto de vista em relação a esses temas, quando, na verdade, são as e os maiores interessadas/os em acessar uma educação de qualidade. Nas

Práxis Educativa, Ponta Grossa, v. 14, n. 3, p. 1049-1065, set./dez. 2019 Disponível em: <http://www.revistas2.uepg.br/index.php/praxiseducativa $>$ 
entrevistas com as e os ocupas, percebemos a falta de espaços deliberativos que envolvem as e os estudantes anterior as ocupações, mesmo nas escolas que tinham grêmio estudantil organizado, como relata uma das entrevistadas: "As direções não entendem que o grêmio estudantil é para andar lado-a-lado, eles enxergam o grêmio como um inimigo. Então, a gente não era visto como uma grande liderança, não era muito apostado" (Estudante entrevistada, 18 anos, set. 2017).

Pela característica de movimento em rede ${ }^{1}$, diversas foram as pautas elencadas pelas ocupações que demonstram a pertinência da abordagem no estudo da realidade da escola pública brasileira.

Os movimentos são simultaneamente locais e globais. Começam em contextos específicos, por motivos próprios, constituem suas próprias redes e constroem seu espaço público ao ocupar o espaço urbano e se conectar às redes da internet. Mas também são globais, pois estão conectados com o mundo inteiro, aprendem com outras experiências e de fato, muitas vezes são estimulados por essas experiências a se envolver em sua própria mobilização. (CASTELLS, 2013, p. 130).

Ao discutirem a questão das funções morais e éticas da escola, tendo por base o deslocamento contemporâneo do foco social para o indivíduo, Barrere e Martuccelli (2001) indicam que a comunicação proposta pelas e pelos jovens é de vital importância para uma oferta qualificada da Política de Educação. Nesse sentido, as ocupações compartilham desse ensinamento, pois ainda que assumam uma postura intransitiva e radical, o conjunto de estudantes propõe com o movimento uma abertura de diálogo para apresentar o seu entendimento sobre um ideal educativo. Em estudo sobre o cotidiano escolar, Barrere e Martuccelli (2001) afirmam que:

Os alunos exigem respeitos horizontais. Para eles a relação pedagógica correta tem uma natureza igualitária e supõe um respeito mútuo e um equilíbrio dos sentimentos. A maioria dos alunos não contesta os alicerces da autoridade, mas pede um tratamento recíproco, exigência incontornável, anterior ao universo de comunicação em que estão imersos. (BARRERE; MARTUCCELLI, 2001, p. 270).

A maneira das juventudes posicionarem-se socialmente em relação à comunicação é permeada por uma frenética produção de materiais difundidos nas redes virtuais. Ainda assim, a dificuldade de fazer-se ouvir nas organizações instituídas pela lógica adulta faz com que as ocupações se configurem como um importante meio de alcançar visibilidade por meio dos discursos que perpassam as ideias do cotidiano juvenil. Para além disso, a dinâmica de estar inserido em um movimento em rede possibilita a transposição de pensamentos que, em certa medida, se fazem uníssonos, por ecoarem situações que se aproximam em função da condição adolescente. Assim, a vivência da ocupação é a vivência de uma experiência modificada; nesse caso, a experiência de escolarização permeada pelos ideais estudantis, que tensionam o entendimento da realidade social e de si, compondo uma constante crítica e autocrítica. "As maneiras pelas quais qualquer geração viva, em qualquer 'agora', 'manipula' a experiência desafiam a previsão e fogem a qualquer definição estreita da determinação" (THOMPSON, 1981, p. 189). Consoante o pensamento de Castells (2013), acerca dos movimentos em rede, entendemos que as ocupações:

São movimentos profundamente autorreflexivos. Questionam-se permanentemente como movimento, e seus participantes como indivíduos, sobre o que são, o que desejam e o que pretendem realizar, que tipo de democracia e sociedade estão almejando e como evitar os imprevistos e armadilhas de tantos movimentos fracassados por reproduzir

\footnotetext{
1 Movimento social independente e autônomo conectado pela rede de internet, mas com características comuns, como o poder de mobilização e abrangência da comunicação em escala global. Castells (2013) discorre acerca dos movimentos em rede contemporâneos em Redes de Indignação e Esperança: movimentos sociais na era da internet.
}

Práxis Educativa, Ponta Grossa, v. 14, n. 3, p. 1049-1065, set./dez. 2019 Disponível em: <http://www.revistas2.uepg.br/index.php/praxiseducativa> 
em si mesmos os mecanismos do sistema que queriam mudar. (CASTELLS, 2013, p. 132, grifo do autor).

O conjunto de estudantes secundaristas engloba principalmente jovens adolescentes, em sua maioria sujeitos com até 18 anos de idade. Essa característica traça uma importante diferenciação entre as ocupações que ocorreram nas escolas básicas, centro técnicos e universidades. A maneira de estar inserido e ser visto no mundo é determinante entre antes e depois dos 18 anos de idade, pois implica diretamente na cidadania desses sujeitos. Assim, interpretamos que as ocupações das escolas públicas assumiram um caráter comunicativo e de protagonismo, que busca, para além das pautas materiais, dialogar acerca da condição adolescente.

O encontro entre o sujeito adulto e adolescente promovido pela escola confronta a barreira da cidadania, no que diz respeito aos direitos e aos deveres, baluartes do Estado Democrático de Direitos. Ao mesmo tempo que é garantido para a criança e o adolescente o acesso à educação como um direito social constitucional (BRASIL, 1988), a escolarização não supera a desigualdade entre sujeitos menores com restritos direitos políticos frente a sujeitos adultos com uma cidadania completa, ainda que seja questionável o entendimento de cidadania impresso nas democracias contemporâneas. Desse modo, afirma Martuccelli (2016, p. 158) que "[...] la reflexión sobre la ciudadanía escolar no puede obviar el hecho que en su seno se produce el encuentro de profesores-mayores-ciudadanos y de alumnos-menores-excluidos legalmente de la ciudadanía".

Pensando nisso, refletimos que, por seu caráter comunicativo, horizontal e autodeterminado, a experiência das ocupações proporcionou para as e os estudantes envolvidas/os uma socialização política diferenciada de seu cotidiano nos diversos âmbitos sociais, ainda que sua condição adolescente tenha implicado no desenvolvimento das ocupações. Nesse sentido, concordamos com Thompson (1981), no entendimento de que as contradições existentes no contexto social fazem com que ocorram "[...] mudanças no ser social que dão origem a experiência modificada; e essa experiência é determinante, no sentido de que exerce pressões sobre a consciência social existente" (THOMPSON, 1981, p. 16). Dessa maneira, a vivência das tensões em relação à condição adolescente proporcionou uma experiência modificada de socialização política na educação, mas não deixou de reproduzir as relações que as e os sujeitos sociais estão implicadas/os, ainda que essa experiência atípica torne mais evidente as contradições, possibilitando repensá-las.

Embora as ocupações se constituam de maneira independente em cada escola, o movimento em rede criou características que as aproximam. Assim, identificamos um perfil comum das ocupações, por meio da leitura de produções acadêmicas que analisam o movimento desenvolvido em diversas regiões do Brasil. Entre outros elementos, observamos que as ocupações se unem nas diferentes pautas que se coadunam na discussão acerca do direito à educação, educação de qualidade, ação política juvenil e o tema no qual nos debruçamos no presente artigo: as expressões da condição adolescente nos processos de socialização política. Desse modo, apresentamos, na seção seguinte, as características comuns das ocupações secundaristas, sob o ponto de vista da pesquisa acadêmica, refletindo a relevância da temática para os estudos acerca da participação política adolescente.

\section{Ocupação das escolas públicas nas pesquisas acadêmicas}

A presente pesquisa tem entre seus objetivos refletir sobre a ação estudantil militante, ponderada pela condição adolescente das e dos secundaristas. Para melhor compreendermos o

Práxis Educativa, Ponta Grossa, v. 14, n. 3, p. 1049-1065, set./dez. 2019 
espaço de fala desses atores sociais, recorremos aos estudos acadêmicos que discutem a socialização política das e dos adolescentes, principalmente os trabalhos recentes, que buscam construir uma narrativa analítica do movimento estudantil de ocupações, com base no seu contexto de produção.

Em pesquisa sobre as ocupações, Borges (2018) destaca, no levantamento do Estado da Arte acerca da participação estudantil e movimento estudantil, que as pesquisas acadêmicas que abordam essas temáticas, em geral, não têm como atores sociais as e os estudantes secundaristas, concentrando-se, em sua maioria, na trajetória de socialização política das e dos estudantes do Ensino Superior. Contudo, a partir de 2017, houve uma considerável modificação nesse cenário, em decorrência da repercussão e extensão das ocupações secundaristas. Em função disso, as pesquisas sobre a participação e o movimento estudantil passaram a focar nesses sujeitos, buscando compreender o fenômeno social de ocupação. Conforme Sposito e Tarábola (2017):

A visibilidade e a intensidade dos protestos e a disseminação rápida das ocupações
estudantis podem ter provocado alguma surpresa, ou mesmo perplexidade, diante dessa
forte capacidade de resistência apresentada por atores até então considerados
irrelevantes ou ausentes da cena pública política. A importância desse conflito foi
percebida pela produção acadêmica, pelos professores e intelectuais engajados que,
ainda no calor dos acontecimentos, buscaram registrar e documentar as mais variadas
formas da organização estudantil. Esforços iniciais de análise foram realizados e
condensados em importantes publicações recentes, como foi o caso do dossiê sobre as
peculiaridades do ensino médio contemporâneo e os jovens (Carrano, 2016), da
publicação de dois dossiês sobre o socialização política (Tomizaki, Silva, Carvalho-Silva,
2016) e resistência estudantil (Moraes e Ximenes, 2016) reunidos na Revista Educação e
Sociedade em fins de 2016, do boletim editado pela ANPEd com vários artigos e
vídeos (Boletim ANPEd, 2016) e do rico trabalho de documentação e
acompanhamento das mobilizações, consolidado no livro Escolas de luta (Campos,
Medeiros e Ribeiro, 2016), entre outros. (SPOSITO; TARÁBOLA, 2017, p. 14).

No levantamento de teses e de dissertações acerca do movimento estudantil, produzidas antes de 2016, verificamos, no campo histórico, uma predominância de estudos localizados temporalmente no período de Ditadura Civil-Militar (BORGES, 2018). E, nesse interim, segundo Martins (2010),

[...] parecem privilegiar os estudantes universitários que eram a maioria, e não têm, como uma de suas preocupações, a distinção da atuação dos estudantes secundaristas. A história dos estudantes do movimento secundarista se apresenta como uma grande lacuna, uma página não escrita a ser trabalhada pelos historiadores. (MARTINS, 2010, p. 66).

Já os estudos e as pesquisas produzidos em Educação, na análise do cotidiano das escolas de Educação Básica, têm dificuldades de reconhecer a participação estudantil em sua dinâmica organizativa própria. Dessa forma, percebemos que, tanto na realidade social quanto na pesquisa acadêmica, o espaço de participação das e dos estudantes é reduzido e, por vezes, desconsiderado na organização escolar, refletindo sua posição política desigual.

Alguns dos trabalhos com os quais dialogamos na pesquisa (PESCUMA, 1990; CARLOS, 2006; FERNANDES, 2001) tendem a privilegiar em suas análises os obstáculos e impedimentos enfrentados pelos jovens do grêmio em detrimento de uma discussão que contemple de forma mais aprofundada as experiências proporcionadas pelo processo participativo. [...]. Reconhecemos a importância de tal discussão, todavia, pensamos que há que se dar um passo à diante no sentido de perceber que a existência de obstáculos e dificuldades para a atuação do grêmio está inserida no processo participativo e não invalida outros tipos de experiências decorrentes do próprio processo. Nesse sentido, a busca é por avançar, na tentativa de preencher as lacunas

Práxis Educativa, Ponta Grossa, v. 14, n. 3, p. 1049-1065, set./dez. 2019 Disponível em: <http://www.revistas2.uepg.br/index.php/praxiseducativa> 
existentes em relação ao processo participativo e às experiências proporcionadas aos jovens no cotidiano escolar. (MARTINS, 2010, p. 17).

Para Martins e Dayrell (2013), o reconhecimento da participação estudantil é afetado, entre outros fatores, pelas representações culturais construídas acerca da juventude. No que se relaciona à socialização política, a falta de maturidade é pontuada entre as justificativas para esse panorama. Segundo Martins e Dayrell (2013), o problema está no não reconhecimento da lógica de ação diversa da lógica adulta, chamada pelos autores de organização desorganizada. O grêmio estudantil é um exemplo desse formato organizativo, pois a atuação das e dos adolescentes nesses coletivos tende a ser desburocratizada e com uma dinâmica própria. "O que parece uma desorganização para o adulto, pode ser uma estratégia de participação para o jovem que divide seu tempo com a escola, o trabalho e o lazer desses coletivos" (MARTINS; DAYRELL, 2013, p. 1280).

Por configurar-se como um movimento em rede, as ocupações aproximam-se de uma organização desorganizada, no sentido apontado por Martins e Dayrell (2013), pois sua dinâmica cotidiana foi realizada de maneira espontânea e autogerida. Isso não quer dizer que as ações não fossem planejadas, mas que, como organização desorganizada, as e os ocupas mantinham espaços para reestruturação do seu cronograma de modo a melhor abarcar a participação de todos, conforme relata uma das estudantes entrevistadas quando questionada sobre a organização do dia a dia das ocupações: "a gente reunia todos os dias pra dizer: 'não deu certo fulano na cozinha', então a gente troca pra ver quem vai fazer o almoço ou quem vai ficar cuidando lá da frente" (Estudante entrevistada, 18 anos, set. de 2017). Nesse sentido, as ocupações convergem com o modo de reprodução dos movimentos em rede que "[...] raramente são programáticos, [...] sendo múltiplas as demandas e ilimitadas as motivações, eles não conseguem formalizar uma organização ou liderança porque seu consenso, seu companheirismo depende de uma deliberação" (CASTELLS, 2013, p. 133).

A maneira como surgiram as ocupações demonstra a potencialidade das organizações desorganizadas juvenis. $\mathrm{O}$ rechaço à burocracia e a identificação solidária, na qualidade de jovem estudante, criou as condições para o surgimento em escala viral - utilizando termo do próprio contexto das redes virtuais - das ocupações, sem necessariamente compartilharem das mesmas demandas.

\begin{abstract}
Os estudantes secundaristas paulistas se inspiraram na experiência chilena e influenciaram um vigoroso movimento de ocupação de escolas que, a partir de fevereiro de 2016, foi retomado no Rio de Janeiro, tendo passado por São Paulo, num outro momento, bem como Ceará, Paraná e Rio Grande do Sul com mais força. Assim conseguiram conquistar uma série de acordos locais que se tornam potentes por refletir reivindicações desses estudantes que foram atendidas pelos governos estaduais, envolvendo melhorias na infraestrutura das escolas, participação democrática nos processos decisórios e escolha dos diretores. Trata-se, a meu ver, do segmento mais potente do contexto de lutas atuais na esfera interconectada que se tece no Brasil. (CASTANEDA, 2017, p. 13).
\end{abstract}

As relações estabelecidas nas ocupações procuram transpor as relações hierárquicas e autoritárias reproduzidas nas escolas. Essa característica de autogestão e horizontalidade advém da crítica à experiência própria das e dos adolescentes, que buscam fazer da ocupação uma vivência diferente do cotidiano escolar, no qual não se sentem ouvidos e não tem poder deliberativo, para além da eleição da direção escolar. Na pesquisa realizada nas ocupações no sul de Minas, Groppo et al. (2017) afirmam que, no dia a dia, as e os ocupas ${ }^{2}$

\footnotetext{
2 Autodenominação utilizadas pelas e pelos estudantes que participaram do movimento estudantil de ocupações.
}

Práxis Educativa, Ponta Grossa, v. 14, n. 3, p. 1049-1065, set./dez. 2019 Disponível em: <http://www.revistas2.uepg.br/index.php/praxiseducativa> 
[...] demonstram autonomia, capacidade de autogestão, organização do espaço, articulação política e protagonismo estudantil, antes só vistos nos documentos e legislações sobre a infância e adolescência, mas muito pouco experimentados na prática, provavelmente porque, pela primeira vez, as experiências estão sendo propostas por eles próprios, os adolescentes e jovens. (GROPPO et al., 2017, p. 152).

Além disso, a literatura demonstra outra característica da socialização política desenvolvida nas ocupações, a saber: a participação direta. "A forma descentralizada do movimento, a democracia direta com a tomada de decisão em assembleia e a distribuição igualitária nas tarefas foram aspectos característicos desse movimento" (PIOLLI; PEREIRA; MESKO, 2016, p. 27). Os movimentos em rede tendem a ter como base organizativa a democracia direta, pois rechaçam os modelos políticos com limitados direitos de participação e a burocracia desses sistemas (CASTELLS, 2013).

\begin{abstract}
Os ocupantes também tentam colocar em curso um novo tipo de gestão nos prédios ocupados: a cultura democrática participativa. Embora, nos últimos anos, o país tenha avançado em alguns aspectos na forma de escolha do gestor escolar, a juventude dá sinais de que simplesmente votar a cada quatro anos para a escolha do diretor não é suficiente. Muitas vezes, a gestão colocada em prática tem um distanciamento hercúleo do plano apresentado à comunidade durante o período eleitoral, muitos gestores, ao tomar posse, esquecem dos compromissos durante à eleição. (REIS, 2017, p. 254).
\end{abstract}

Tratando da autogestão, da horizontalidade e da participação direta, não afirmamos que exista uma predisposição revolucionária na juventude, mas entendemos as contradições e as tensões existentes nas relações estudantis que formam o contexto de produção das ocupações. Afirmar isso faz parte do reconhecimento da existência de um dualismo intencional na representação cultural da juventude, que acaba por exercer pressão na conduta das e dos jovens. Nessa lógica, por um lado é propagada a ideia de que as e os jovens não se interessam pela política, nem são participativos; por outro, existe uma visão difundida da juventude revolucionária, ligada a um passado de lutas e de resistências.

A sociedade brasileira atualmente tende a comparar o jovem de hoje com o de outros tempos. A questão, se tratada dessa forma, pode desencadear uma visão simplista sobre a participação estudantil e não conseguir abarcar a complexidade das mudanças ocorridas na nossa sociedade e na condição vivida pelos jovens. No que tange ao movimento estudantil, as lembranças dos anos da ditadura militar e os movimentos de 68, bem como, "os caras pintadas" do "Fora Collor" em 92, são representações que acabaram por se tornar um paradigma de participação. Na década de 1960, a representação que se construiu em torno de ser jovem participativo estava quase que obrigatoriamente ligada à condição de ser estudante, com destaque para os estudantes universitários. Contudo, há que se ressaltar que esses jovens estudantes eram na realidade uma pequena parcela da juventude brasileira no momento em questão. (MARTINS, 2010, p. 64).

A responsabilidade revolucionária imputada à juventude também repercute na falta de reconhecimento do formato organizativo das e dos jovens, que muitas vezes foge ao padrão das organizações políticas, compreendendo manobras e instrumentos de comunicação diversos que permitem diferentes níveis de envolvimento. Por meio da deslegitimação do comportamento contrastante ao adulto, cria-se uma brecha cultural geracional que "[...] tiende, así, a convertirse en una división generacional que rompe la continuidad cultural entre ellas" (MARTUCCELLI, 2016, p. 162). A falta de identificação dessas estratégias de participação da juventude leva a crer que dados períodos sejam desprovidos de sua ação política.

Em nosso país, observam-se claramente as dificuldades de compreensão da crise da participação estudantil presentes em alguns estudos, mas é preciso considerar que, ao lado dessa lacuna teórica, foi criado um leque de representações sociais no interior do

Práxis Educativa, Ponta Grossa, v. 14, n. 3, p. 1049-1065, set./dez. 2019 Disponível em: <http://www.revistas2.uepg.br/index.php/praxiseducativa $>$ 
senso comum, que constituíram como modelo de ação coletiva de jovens essas práticas de participação, excluindo outras possibilidades de análise. (SPOSITO, 2000, p. 79).

Contradizendo uma concepção simplista de participação, as ocupações demonstram a pluralidade cultural e existencial da juventude que refletem em suas ações de resistência e de transformação. Nas pesquisas, identificamos o potente canal de comunicação criado pelas e pelos ocupas, no qual apresentam a sua compreensão da realidade social problematizando seu papel nela. Desse modo, ao realizarmos esse exame da produção intelectual recente sobre as ocupações, tendemos a reconhecer a afirmação de Reis (2017) como ponto de partida importante para a compreensão desse fenômeno:

Ao contrário do que se imaginava, os jovens estão, sim, interessados na política. Todavia, não se sentem representados pelos partidos políticos existentes no país. Talvez isso seja consequência da complexa crise ética e política em que o Brasil mergulhou nos últimos anos. (REIS, 2017, p. 253).

O cenário das ocupações diferencia-se das representações sociais vulgares da juventude, tanto das e dos estudantes revolucionárias/os quanto apolíticas/os, pois explicita um formato organizativo diferenciado de participação política juvenil. A organização desorganiz̧ada das ocupações é refletida em sua vivência cotidiana, que propôs uma nova configuração dos espaços e dos papéis dentro das escolas, transpondo as barreiras institucionais ao que se refere ao poder e à autoridade. Esse contexto torna a temática potente para compreendermos as peculiaridades da organização e da participação juvenil, principalmente vinculada à condição adolescente das e dos estudantes.

Tanto na nossa pesquisa quanto na leitura de outros estudos acerca das ocupações, identificamos que as assembleias formaram o espaço privilegiado de deliberação. Nas primeiras ocupações ocorridas em São Paulo, foi elaborada uma cartilha de Como Ocupar sua Escola? baseada no material que circulou entre as ocupações das escolas chilenas. Nessa cartilha, a assembleia é apontada como o primeiro passo da ocupação. Verificamos nas entrevistas com as e os estudantes que, mesmo sem o conhecimento da cartilha, a assembleia foi adotada em todas as ocupações, o que revela o caráter horizontal do movimento. "A horizontalidade é um dos pontos importantes desse movimento. Não há uma liderança definitiva, porém todos influenciam e participam dos rumos que a ocupação vai percorrer" (GROFF DA SILVA; SILVA, 2017, p. 236).

Segundo a literatura, horizontalidade, democracia direta, autogestão e comunicação em rede são características comuns às ocupações. Em função disso, buscamos analisar essas experiências peculiares à luz dos termos "condição adolescente", discutido por Martucelli (2016), e "experiência", elaborado por Thompson (1981). O objetivo é compreendermos tanto as experiências que acompanhamos na cidade de Caxias do Sul, quanto, em uma perspectiva ampla do movimento, a maneira que a condição adolescente influiu na socialização política ocorrida nas ocupações.

\section{Termos de referência para análise da temática}

As ações políticas das e dos ocupas pode ser descrita como transformadoras, tendo em vista a modificação do espaço escolar durante o período de ocupação. O estudo empreendido sobre a temática deixa claro que os resultados materiais das reivindicações feitas pelas ocupações não lograram grande êxito, para além de barrar a reestruturação da rede de ensino em São Paulo e promessas pontuais de reforma das estruturas das escolas e maior repasse de verbas para a

\footnotetext{
${ }^{3}$ Material encontrado na página de Facebook da União Brasileira dos Estudantes Secundaristas (Ubes).
} 
Política de Educação. Contudo, nossa hipótese é que as aprendizagens políticas do movimento proporcionaram uma expressiva mudança subjetiva nas e nos adolescentes envolvidos, sendo o cabedal de transformação das ocupações.

Essas mudanças expressaram-se no dia a dia das ocupações. Por isso, adotamos como suporte analítico o termo "experiência", discutido por Thompson (1981), sob o ponto de vista do materialismo histórico dialético. Para Thompson (1981), a experiência é um fator de vital importância para a compreensão dos processos históricos, que foi negligenciado por longa tradição marxista economicista, com uma visão restrita e determinista da sociedade de classes. Por meio desses estudos, Thompson (1981) inclui, na escrita da história, o cotidiano das e dos sujeitos comuns, compreendendo que a vivência vem antes da estrutura, como exemplifica ao tratar a categoria classe social:

Nenhuma categoria histórica foi mais incompreendida, atormentada, transfixada e deshistorizada do que a categoria de classe social; uma formação histórica autodefinidora, que homens e mulheres elaboram a partir de sua própria experiência de luta, foi reduzida a uma categoria estática, ou a um efeito de uma estrutura ulterior, das quais os homens não são os autores mas os vetores. (THOMPSON, 1981, p. 57).

A experiência é, segundo Thompson (1981), o termo que vincula o modo de produção ao processo histórico. De acordo com a mesma obra, a experiência nada mais é do que a vivência da cultura, das relações econômicas, das tradições, dos costumes, dos valores, das relações de produção, das vivências que dão sentido às estruturas sociais. É por meio do conhecimento das experiências do cotidiano do ser social que podemos compreender os processos sociais e econômicos em sua realidade.

\begin{abstract}
Os homens e mulheres retornam como sujeitos, dentro deste termo - não como sujeitos autônomos, "indivíduos livres", mas como pessoas que experimentam suas situações e relações produtivas determinadas como necessidades e interesses e como antagonismos, e em seguida "tratam" essa experiência em sua consciência e sua cultura (as duas outras expressões excluídas pela prática teórica) das mais complexas maneiras (sim, "relativamente autônomas") e em seguida (muitas vezes, mas nem sempre, através das estruturas de classe resultantes) agem, por sua vez, sobre sua situação determinada. (THOMPSON, 1981, p. 182).
\end{abstract}

Esse diálogo, entre a vivência e a consciência, permite a ação de transformação do meio social e de si. Nessa perspectiva, as ocupações perfilam como uma experiência de aprendizagem compartilhada, elaborada reflexivamente pelas e pelos sujeitos, fazendo sentido em suas histórias de vida, no coletivo e nos processos históricos. As contradições registradas no desenvolvimento das ocupações podem ser traduzidas como um movimento dialético, que agrupa em seu cerne reproduções, tensões e transformações, característico a um processo crítico de transformação da consciência social (THOMPSON, 2001).

Nesse sentido, a condição adolescente aparece como um dos valores que influencia na experiência cotidiana das e dos estudantes. Ainda que esse papel se modifique durante as ocupações, levando as e os ocupas a se identificarem mais como militantes, continuam implicados por sua condição adolescente, visto que as ocupações não se desgrudam de seu contexto de produção. "El adolescente es un miembro pleno de la sociedad... pero sin derechos políticos y en una situación de moratoria puesto que debe adquirir su futura posición social" (MARTUCCELLI, 2016, p. 160).

A condição adolescente, segundo Martuccelli (2016), é determinante na cidadania escolar, pois tensiona os três aspectos que constituem o sujeito cidadão e cidadã: o reconhecimento de direitos dentro de uma coletividade, ser ator social e preservar o civismo. Em vista disso, 
Martuccelli (2016) ainda afirma que a cidadania adolescente é uma cidadania pela metade, pois é socialmente limitada nesses três aspectos. A experiência cidadã adolescente é reduzida em direitos políticos, abrange direitos civis e sociais diferenciados e o civismo nem sempre faz sentido nas culturas juvenis.

Segundo Martuccelli (2016), a justificativa para a restrição da participação política das e dos adolescentes está na consideração de que lhes falta maturidade. Em vista disso, consideramos que essa desqualificação é socialmente intencional, à medida que garante a manutenção da posição desigual dessa parcela da população em relação à cidadania, "[...] lo esencial es comprender que la descalificación ciudadana de los adolescentes se basa en una representación cultural particular - como ayer fue el caso con los obreros y las mujeres" (MARTUCCELLI, 2016, p. 156). Isso nos permite refletir que as ocupações não implicam apenas no cotidiano das escolas, mas, sim, nos valores políticos e sociais nelas reproduzidos, o que explicaria as reações antagonistas violentas contra um movimento que se pretende não violento. Assim, quando tratamos de um movimento em rede:

\footnotetext{
Um dos principais temas do debate é a questão da violência com que os movimentos, por toda parte, se defrontam em sua prática. Em princípio, eles são não violentos, em geral se envolvendo, em sua origem, na desobediência civil, pacífica. Mas tendem a se engajar na ocupação do espaço público e em táticas contenciosas com o propósito de pressionar autoridades políticas e organizações empresariais, de vez que não reconhecem a viabilidade de uma participação justa nos canais institucionais. Assim, a repressão, com diferentes níveis de violência, dependendo do contexto institucional e da intensidade do desafio apresentado pelo movimento, é uma experiência recorrente em todo o processo de ação coletiva. (CASTELLS, 2013, p. 132).
}

Ainda que a violência imputada às e aos adolescentes tenham sido negativamente significativas, refletimos que as ocupações foram experiências de socialização política excepcionais, pois, como afirma Thompson (2001, p. 261), “[...] somente em circunstâncias excepcionais as pessoas realmente vão além de sua experiência local, de seus valores vividos e apresentam um desafio mais amplo". Nesse sentido, verificamos que o movimento proporcionou a vivência de uma experiência de cidadania modificada para as e os ocupas, que elucidaram e transformaram sua consciência acerca da educação, da participação política e de sua condição adolescente. Assim, cabe analisarmos as ocupações no diálogo com seu meio de produção e, também, como uma experiência modificada em relação à sua realidade social.

\section{Condição adolescente nas ocupações de Caxias do Sul}

A pesquisa acerca das ocupações estudantis das escolas públicas em Caxias do Sul iniciou conjuntamente à adesão das primeiras escolas da cidade ao movimento em 2016. Embora as ocupações tenham mantido um formato organizativo semelhante nas diversas cidades do país, a motivação das e dos ocupas foi diferente conforme a região e o período que compreendeu cada ação. No cenário político do estado do Rio Grande do Sul, conforme Severo e San Segundo (2017), o impulso inicial das e dos estudantes foi a tentativa de implementação dos PL 190/2015, Escola Sem Partido, e PL 44/2016, que previa o credenciamento de Organizações Sociais (OSs) para a administração do ensino público, dentre outros serviços do Estado.

Além dessas pautas em relação à rede estadual de educação, destacam-se as péssimas condições estruturais das escolas, com precário acesso a materiais didáticos e merenda escolar, além da desvalorização salarial das e dos professoras/es. Fatores que refletem os anos de investimento insuficiente na área de educação no estado do Rio Grande do Sul. Após as ocupações de algumas escolas na capital de Porto Alegre, as e os estudantes de Caxias do Sul

Práxis Educativa, Ponta Grossa, v. 14, n. 3, p. 1049-1065, set./dez. 2019 Disponível em: <http://www.revistas2.uepg.br/index.php/praxiseducativa> 
tiveram mais perto de si uma experiência exitosa para seguir. Como relata uma das estudantes entrevistadas na pesquisa após o término das ocupações na cidade, a identificação com as situações problemas e a solidariedade com as e os demais participantes do movimento motivaram a ocupação de sua escola:

$\mathrm{Na}$ verdade, tudo começou nas ocupações que estavam ocorrendo pelo Brasil. Nós tínhamos ficado sabendo que [outra escola] queria ocupar; já tinha uma ocupação parcial ali. E um amigo meu me perguntou como é que estava funcionando e tudo mais, porque eu era a presidente do grêmio estudantil da escola. Eu expliquei pra ele e ele pediu: "por que a gente não ocupa?” Eu falei pra ele que existiam motivos. Ele falou que motivos, pra nós, não faltavam. [...]. A gente sabe que tem escola que tá quase caindo, digamos assim. A gente tinha problemas internos, que eram fáceis de resolver, mas que estavam sendo difíceis para nós. E o problema ali, Caxias do Sul, que estava se acumulando e ninguém estava fazendo nada. (Estudante entrevistada, 17 anos, set. 2017).

Embora as péssimas condições materiais da rede estadual de ensino estejam entre os principais motivos geradores das ocupações das escolas no Estado, também foi o grande empecilho para o desenvolvimento de algumas manifestações. Durante a visita a uma das escolas ocupadas, as e os ocupas relataram que, por meio do movimento, ampliaram seu conhecimento e sua comunicação com outras e outros estudantes, tanto com as e os que já estavam fazendo parte de ocupações, quanto as e os que tinham intensão de fazer em sua escola. Em função disso, sabiam que outra escola seria ocupada, mas sua estrutura era tão precária que não havia condições das e dos estudantes pernoitarem nela, pois parte do prédio havia sofrido um incêndio e não foi restaurado, além de ter instalações elétricas sem proteção. Por esse motivo, a escola citada não chegou a ser ocupada, apenas foram realizadas manifestações pontuais pelas e pelos estudantes, que envolveu paralisação das aulas em alguns dias.

Nossa primeira visita de campo realizada a uma das ocupações foi no exato dia em que as e os estudantes decidiram aderir ao movimento. A visita ocorreu no final da tarde quando já havia sido realizada a assembleia inicial. Nesse momento, havia cerca de dez estudantes, as e os professoras/es do turno da noite, a direção, a secretaria da escola e a irmã mais velha de uma das estudantes. Nas quatro ocupações pesquisadas, verificamos que a Seduc-RS exigiu que houvesse ao menos uma pessoa maior de 18 anos acompanhando as ocupações durante a noite, bem como cada adolescente que permanecesse teria de ter uma autorização assinada pelo seu responsável legal, para que não fossem tomadas medidas de proteção ao menor, como acionamento do conselho tutelar e retirada involuntária das e dos estudantes da escola.

Essas exigências expõem a relação desigual das e dos adolescentes frente à cidadania. Ficou claro durante as ocupações que a liberdade de manifestação das e dos estudantes teve como entrave a sua condição de sujeito tutelado. Nessa escola visitada, inclusive o aspecto juvenil da irmã de uma das estudantes, que acompanharia a ocupação durante a noite, foi questionado. A responsável, após reunir-se com a diretora, relatou que foi inquerida de maneira rude e desconfiada acerca de sua idade e função laborativa. Nessa conversa, foi-lhe entregue um ofício da Seduc-RS que pretendia guiar e estabelecia algumas normas de comportamento durante a ocupação. Apenas no dia seguinte, as e os ocupas ficaram sabendo, por meio do contato com estudantes de outras escolas ocupadas, que o responsável maior de idade que deveria passar a noite na ocupação poderia ser um ou uma estudante do próprio movimento.

Nessa primeira visita de campo, visualizamos que as e os ocupas estavam bastante nervosas/os ao estabelecer a sua autoridade na escola por meio da ocupação, sendo presenciado inclusive um conflito com exaltação verbal entre a secretária e um dos adolescentes que estava na recepção da escola. O motivo da discussão foi porque a secretária não queria que o estudante 
mantivesse o portão fechado, mas ele insistiu em deixá-lo trancado, pois facilitaria a organização da ocupação. Alguns estudantes do noturno estavam chegando, durante o período que acompanhamos a ocupação, sendo informado pelo ocupa que ficara responsável pelo portão que não havia aula. Provavelmente pela tensão do embate com a direção e a secretaria, o ocupa não conseguiu dialogar com as e os estudantes do noturno, pois apenas informou que não haveria aula, dispensando as e os demais estudantes, sem convidar para somarem ao movimento. No que se refere a menor idade das e dos estudantes, no início da ocupação, é apresentado outro conflito no relato de uma das adolescentes entrevistadas, em relação à autorização de mães, pais ou outros responsáveis:

A gente fez uma votação, não era a grande maioria que estava presente lá dentro, mas era a grande maioria que apoiava e esse é o diferencial que as pessoas não veem, porque era uma minoria que estava ocupando, mas não. Eu conheço um pessoal, e o pessoal entende o que estava acontecendo. Só que o problema realmente são os pais. Até, eu tive dificuldades, no início, com os meus, mas depois que eles viveram e entraram dentro da realidade ali da ocupação, eles viram que era uma coisa bem bacana, era uma luta válida. E esse era mais o problema das pessoas que não estavam ali junto, sabe, era o bloqueio dos pais. (Estudante entrevistada, 17 anos, fev. 2017).

Em relação à condição adolescente, em visita de campo, também identificamos a tentativa de desqualificação do movimento, sendo apontada a questão de falta de maturidade pela idade das e dos ocupas. Foi-nos relatado, em uma das visitas, que a diretora teria verbalizado que a ocupação era uma "birra de adolescentes imaturos". Relatos como esse surgiram posteriormente na tentativa de desmobilizar as e os ocupas que foram taxados como "desocupados", conforme relata uma das estudantes de outra ocupação:

Notei com pouco tempo que estou aqui, que todas as críticas e xingamentos chulos que estamos recebendo, são apenas uma parte do que nossos professores sofrem, TODOS os dias, de pessoas que não fazem ideia do que é a realidade de uma escola pública e estadual. Fomos chamados de "vagabundos", "desocupados", alegaram que estamos agradecendo porque não têm aula, entre outras coisas muito piores que nos atingiu de certa forma. (Texto coletado da página de Facebook da ocupação, maio 2016).

$\mathrm{Na}$ primeira escola visitada, conversamos com um dos professores, que relatou estar apreensivo em relação à postura da direção com as e os estudantes. Apesar de haver uma greve da categoria de professores do estado, as e os professoras/es da escola visitada não haviam aderido, mas, nessa conversa, foi afirmado que, com a ocupação, a partir do dia seguinte, um grupo de professores também paralisaria as suas atividades.

Conforme verificamos na página de Facebook dessa ocupação, o primeiro dia de ocupação bem como a Assembleia foram relatadas passo a passo na rede social, enquanto estava ocorrendo, o que auxiliou a espalhar rapidamente a notícia. A utilização desse meio em que as e os adolescentes são apropriados culturalmente possibilitou que logo no início fossem recebidas doações de comida, cobertores, entre outros mantimentos básicos. Essa ação comunicativa é característica dos movimentos sociais contemporâneos e nos fala da organização peculiar da juventude militante.

Historicamente, os movimentos sociais dependem da existência de mecanismos de comunicação específicos: boatos, sermões, panfletos e manifestos passados de pessoa a pessoa, a partir do púlpito, da imprensa ou por qualquer meio de comunicação disponível. Em nossa época, as redes digitais, multimodais, de comunicação horizontal, são os veículos mais rápidos e mais autônomos, interativos, reprogramáveis e amplificadores de toda a história. As características dos processos de comunicação entre indivíduos engajados em movimentos sociais determinam as características organizacionais do próprio movimento: quanto mais interativa e autoconfigurável for a comunicação, menos hierárquica será a organização e mais participativo o movimento.

Práxis Educativa, Ponta Grossa, v. 14, n. 3, p. 1049-1065, set./dez. 2019 Disponível em: <http://www.revistas2.uepg.br/index.php/praxiseducativa> 
É por isso que os movimentos sociais em rede da era digital representam uma nova espécie em seu gênero. (CASTELLS, 2013, p. 15).

O fato de nossos primeiros contatos com as ocupações terem sido logo no início do movimento em Caxias do Sul foi profícuo para identificarmos as restrições políticas que a condição adolescente apresentou a esses atores sociais. Em função disso, pudemos visualizar no desenvolvimento das ocupações a modificação da relação de autoridade e poder estabelecida nas escolas. Concordamos com Severo e San Segundo (2019, p. 7) em sua afirmação de que "[...] tais processos de socialização autônomos são potencializados quando as juventudes não veem canais de comunicação abertos com o poder público e buscam formas de relações sociais alternativos, ocorrendo tal produção, nesse caso, no espaço escolar".

Durante as ocupações, as e os estudantes passaram a ser as e os principais agentes deliberativos nas escolas, contrapondo o cotidiano escolar, no qual a participação adolescente muitas vezes é limitada à atuação no grêmio estudantil. Registramos, nas ocupações de Caxias do Sul, a experiência de uma organização horizontal e autogerida, embora, no início, como relata uma das estudantes entrevistadas, a tendência tenha sido a de reproduzir as relações de poder cotidianas, principalmente no que se refere à tutela:

\begin{abstract}
No início, vou dar um exemplo bem simples, eu estava em casa na primeira noite, super preocupada com eles que estavam dormindo lá, eles ligaram pra mim: "dá pra gente abrir o pátio e jogar uma bola?”, as 6h da tarde. Então, eu disse: "Gente, não precisa me ligar pra perguntar se pode", mas depois de uma semana... Na escola a gente tem que pedir autorização até pra ir ao banheiro. É que tem aquele sentimento de hierarquia, de alguém que é mandado pra qualquer coisa. Se tu fizer por vontade própria vai estar errado. (Estudante entrevistada, 17 anos, fev. 2017).
\end{abstract}

A Assembleia inicial representou para o movimento estudantil de ocupações a legitimação da ação nas escolas. A votação, além de criar um consenso e compartilhar a responsabilidade, fez com que as e os estudantes construíssem coletivamente as pautas das ocupações. Essa discussão sobre as condições das escolas, mas sobretudo acerca da Política Pública de Educação, reflete as temáticas latentes do direito à educação e da educação de qualidade. Além disso, o protagonismo estudantil, no cenário inicial das ocupações, foi decisivo para a apropriação política do movimento pelas e pelos adolescentes. Assim como outros movimentos em rede, as ocupações apresentaram um distanciamento de organizações e partidos políticos. Isso aparece destacado em uma das visitas realizadas em uma escola que já estava há uma semana de ocupação, onde havia um cartaz na fachada dizendo que as organizações $\mathrm{UJS}^{4}$ e UBES ${ }^{5}$ não eram bem-vindas.

A prerrogativa de construção de um movimento autônomo, sem vínculo com as instituições e as representações políticas consolidadas, fez com que as e os adolescentes trouxessem experiências culturais próprias de seus meios para as ocupações, aprendendo com seus pares no convívio cotidiano. Assim como em Caxias do Sul, as e os estudantes autointitulados como independentes foram a maioria em outras regiões. Groppo, Rossato e Costa (2019, p. 62) destacam, em artigo acerca das ocupações no sul de Minas, a fala de um dos estudantes, sem vínculo político com partido ou movimento social anterior às ocupações, que converge nesse sentido: "[...] politicamente, a impressão é que a gente perdeu tudo, mas o que vai ficar na história é o movimento conseguir aglutinar os estudantes”.

Em contraste à potencialização do movimento por ser construído de maneira autônoma, o afastamento de entidades com experiência de luta pode ser interpretado como um dos fatores

\footnotetext{
${ }^{4}$ União da Juventude Socialista, organização juvenil do Partido Comunista do Brasil (PCdoB).

${ }^{5}$ União Brasileira dos Estudantes Secundaristas, entidade política representante dos estudantes do ensino básico.
} 
que facilitou a exposição das e dos estudantes a reações violentas agravadas por sua condição adolescente. Como tratamos anteriormente, legalmente esses sujeitos são assistidos por uma legislação específica que os "protege", sendo "[...] dever da família, da comunidade, da sociedade em geral e do poder público" (BRASIL, 1990) assegurar as condições que garantam seus direitos. Todavia, a condição de sujeito tutelado e, consequentemente, incapaz de avaliar e tomar a melhor decisão para si e para a sociedade, o expõe a violência moral e física admitida pelo Estado. A exemplo disso, apresentamos o trecho de uma nota publicada no Facebook, na qual as e os estudantes denunciam as agressões sofridas na ocupação:

\begin{abstract}
Durante esses 26 dias de ocupação foi articulado em Caxias do Sul o denominado movimento Desocupa já, o qual tomamos conhecimento através de diferentes redes sociais. O teor do conteúdo desse movimento desde o início tem sido a utilização da força para fazer a desocupação das escolas ocupadas nessa cidade. $\mathrm{Na}$ manhã da segunda-feira passada, 06 de junho, esse movimento realizou a invasão (lembrando, que nós, desde o início, recebemos as chaves) da escola, quebrando os cadeados e correntes que havíamos colocado para segurança do espaço físico da escola e nossa segurança pessoal. A escola está localizada em uma região tida como violenta, nos primeiros dias de ocupação sofremos uma tentativa de arrombamento e por esse motivo os acessos estavam trancados. O movimento Desocupa já, composto, na sua maioria, por não alunos, arrebentou nossos cadeados e correntes, nos agrediu verbalmente e se instalou nos blocos A e B da escola. Desde então temos vivido uma rotina diária de ameaças de agressão física e até mesmo de morte. (Publicação da página de Facebook de uma das escolas ocupadas em Caxias do Sul, junho 2016).
\end{abstract}

As reações violentas praticadas contra o movimento foram apenas uma parte das dificuldades enfrentadas pelas e pelos ocupas, que relatam o frio, as incertezas e os temores durante as ocupações. Ainda assim, a dialética da experiência das ocupações fez com que mesmo essas vivências negativas se convertessem em aprendizagem, que modificou a consciência social das e dos estudantes sobre a educação. Em entrevista, um dos estudantes que fez parte da ocupação na escola atacada pela organização Desocupa Já afirma que:

Do meu ponto de vista - e tenho certeza de que 100\% dos estudantes que ocuparam acho que quando a gente vê essas questões de ser oprimido dentro da escola, devido ao fato de ocupar, dá mais vontade pra lutar, dá mais vontade pra mudar essa relação de poderio dentro da escola. (Estudante entrevistado, 18 anos, set. 2017).

Assim, as experiências de ocupação não podem ser vistas apenas em relação aos avanços políticos materiais alcançados pelas e pelos estudantes, mas deve ser compreendida na complexidade e nas contradições que envolvem uma experiência modificada, que atua principalmente na mudança da consciência social das e dos sujeitos participantes (THOMPSON, 1981). Conforme a entrevista com uma das estudantes, as mudanças institucionais foram poucas, mas alcançá-las por meio da luta estudantil gerou um grande impacto no entendimento das e dos ocupas em relação ao seu papel social para o aprimoramento da política de educação:

O projeto de ensino seria: ter uma gestão democrática. Então, falar com diretor, falar com vice-diretor, com professor, se tornou algo muito mais acessível, não porque essas pessoas, esses cargos se tornaram mais acessíveis, mas porque o estudante se tornou mais. Ele viu que é o lugar dele. A escola é um lugar do estudante. É um lugar onde ele toma as decisões em conjunto com os outros e não algo que vem pronto. (Estudante entrevistada, 17 anos, fev. 2017).

Consoante a isso, outra estudante, embora tenha se sentido perseguida na escola após a ocupação, o que gerou sua reprovação, declara que participar do movimento potencializou seu desenvolvimento pessoal e a sua consciência social, o que a faz encarar com coragem as repercussões que a prejudicaram:

Práxis Educativa, Ponta Grossa, v. 14, n. 3, p. 1049-1065, set./dez. 2019 Disponível em: <http://www.revistas2.uepg.br/index.php/praxiseducativa $>$ 
Eu sempre fui dos movimentos sociais. Então, eu já tinha uma ideia do que era, das lutas e tal. Só que na ocupação a gente tinha palestra de professores, de outras pessoas, e foi muito construtivo, porque todo dia era um debate sobre a educação, sobretudo. Então, só carretou pra mim, cada vez mais, continuar nos movimentos sociais e eu aprendi muita coisa, tive muito conhecimento. Eu até hoje digo que foi uma das melhores coisas que me aconteceu. Eu posso ter rodado, mas o conhecimento que eu adquiri na ocupação, eu não adquiri em nenhum outro lugar. E o conhecimento é coisas que ninguém pode tirar da gente. (Estudante entrevistada, 18 anos, set. 2017)

Desse modo, consideramos que as ocupações foram transformadoras, pois, na perspectiva da experiência, permitiram que as e os ocupas experimentassem um local de fala e participação completamente distinto de seu cotidiano, aglutinando a sua história de vida e ao seu grupo social novos saberes e posicionamentos políticos. Ao que se refere à condição adolescente, ainda que as tensões dessa posição continuassem presentes, as ocupações permitiram o questionamento e tornaram evidentes as contradições da cidadania escolar. Assim, para além de qualquer ganho objetivo em relação às escolas ou aos sistemas de ensino, destacam-se as mudanças subjetivas das e dos estudantes, que tendem a ser mais duradouras e quiçá socialmente mais relevantes.

\section{Considerações finais}

O processo de ocupação das escolas públicas diz respeito à experiência social de escolarização, principalmente em relação ao espaço político das e dos adolescentes frente à cidadania escolar. Embora grande parte das e dos estudantes envolvidos não tenham vivências anteriores de participação em organizações políticas, as ocupações demonstram o interesse e a importância da temática para essas e esses sujeitos, que indicam e tensionam os limites da democracia em seu formato organizativo hodierno. Ainda assim, concordamos com Groppo et al. (2017) na afirmação de que o movimento estudantil de ocupações apenas foi possível pelo acúmulo das experiências dos coletivos estudantis e pelos diálogos intergeracionais.

Conforme argumentamos ao longo do artigo, o estudo do movimento de ocupações é socialmente relevante por possibilitar a reflexão acerca da participação política adolescente, que, em contexto comum, muitas vezes, tende a interpretações dualistas, que consideram a juventude apolítica ou limitam suas ações a personagens revolucionários. Nesse contexto, o movimento estudantil de ocupações se apresenta como um fenômeno importante a ser compreendido pela pesquisa acadêmica, seja pela lacuna existente sobre o histórico de atuação das e dos estudantes secundaristas, seja pela falta de reconhecimento da organização desorganizada da juventude, como forma desses atores sociais se manterem politicamente ativos.

As limitações enfrentadas pelas e pelos estudantes em relação a sua condição adolescente também são instrumentos de aprendizagem nas ocupações, visto que, por um lado, se destaca a contradição de sua cidadania, que, em partes, é tutelada e resguardada com uma série de direitos que visam o desenvolvimento integral das e dos adolescentes, mas, por outro lado, os considera sujeitos imaturos e incompletos, incapazes de reconhecer o melhor para si e para a sociedade. Assim, visualizamos que, na manutenção da condição política desigual das e dos adolescentes, admite-se tanto pela sociedade quanto pelo Estado o uso da violência desproporcional contra o movimento de ocupações. Em vista disso, como uma resposta a esse papel político desigual, as ocupações apresentam uma nova democracia, nas experiências desenvolvidas nas escolas, que rechaça a burocracia e a manipulação dos sistemas políticos representativos e propõe a horizontalidade da participação direta.

Conforme Thompson (1981), a análise da experiência cotidiana permite-nos compreender as transformações no ser social que a longo prazo modificam os processos 
históricos. As ocupações configuram em si uma experiência modificada de escolarização, embora vivenciada em um período determinado, que permitiram as e os estudantes se expressarem de maneira protagonista na socialização política nas escolas. Desse modo, consideramos que, essencialmente, a experiência das ocupações potencializou a transformação subjetiva das e dos ocupas, possibilitando uma compreensão diferenciada acerca da educação, de seu papel social e da importância da participação política para tornar efetiva a democracia.

\section{Referências}

BARRERE, A.; MARTUCCELLI, D. A escola entre a agonia moral e a renovação ética. Educação \& Sociedade, Campinas, v. 22, n. 76, p. 258-277, out. 2001. DOI: http://dx.doi.org/10.1590/S0101-73302001000300014

BORGES, S. G. A dialética das experiências escolares na emergência da prática de ocupar e resistir. 2018. 139 f. Dissertação (Mestrado em Educação) - Universidade do Vale do Rio dos Sinos, São Leopoldo, 2018.

BRASIL. Constituição (1988). Constituição da República Federativa do Brasil. Brasília, DF: Senado, 1988.

BRASIL. Lei no. 8.069, de 13 de julho de 1990. Dispõe sobre o Estatuto da Criança e do Adolescente e dá outras providências. Diário Oficial da União, Brasília, DF, 16 jul. 1990.

CASTAÑEDA, M. Mobilização e ocupações dos espaços físicos e virtuais: possibilidades e limites da reivindicação da política nas metrópoles. Cadernos IHUideias, São Leopoldo, v. 15, n. 255 , p. $1-24,2017$.

CASTELLS, M. Redes de indignação e esperança: movimentos sociais na era da internet. Rio de Janeiro: Zahar, 2013.

GROFF DA SILVA, B. V.; SILVA, E. C. H. da S. "Uma pá de ocupação": ocupações escolares e atuação juvenil no Rio Grande do Sul (2016). Teias, Rio de Janeiro, v. 18, n. 50, jul./set. 2017. DOI: https://doi.org/10.12957/teias.2017.27072

GROPPO, L. A.; ROSSATO, M. H. L.; COSTA, M. C. da S. Extensão, pesquisa e engajamento: aprendizado de lutas e dores no seminário memorial das ocupações estudantis. Conexão UEPG, Ponta Grossa, v. 15, n. 1, p. 59-68, jan./abr. 2019. DOI: https://doi.org/10.5212/rev.conexao.v.15.11.0008

GROPPO, L. A. et al. Ocupações no sul de Minas: autogestão, formação política e diálogo intergeracional. ETD - Educação Temática Digital, Campinas, v. 19, n. 1, p. 141-164, jan./mar. 2017. DOI: https://doi.org/10.20396/etd.v19i1.8647616

MARTINS, F. A. S. A voz do estudante a educação pública: um estudo sobre participação de jovens por meio do grêmio estudantil. 2010. 168 f. Dissertação (Mestrado em Educação) Universidade Federal de Minas Gerais, Belo Horizonte, 2010. 
MARTINS, F. A. S.; DAYRELL, J. T. Juventude e participação: o grêmio estudantil como espaço educativo. Educação e Realidade, Porto Alegre, v. 38, n. 4, p. 1267-1282, out./dez. 2013. DOI: https://doi.org/10.1590/s2175-62362013000400014

MARTUCCELLI, D. Condición adolescente y ciudadanía escolar. Educação \& Realidade, Porto Alegre, v. 41, n. 1, p. 155-174, jan./mar. 2016. DOI: https://doi.org/10.1590/2175$\underline{623660050}$

PIOLLI, E.; PEREIRA, L.; MESKO, A. de S. R. A proposta de reorganização escolar do governo paulista e o movimento estudantil secundarista. Crítica Educativa, Sorocaba, v. 2, n. 1, p. 21-35, jan./jun. 2016. DOI: https://doi.org/10.22476/revcted.v2i1.71

REIS, V. \#Ocupar e resistir: estudantes catarinenses em defesa da escola pública. Argumentos Pró-Educação, Pouso Alegre, v. 2, n. 5, p. 235-258, maio/ago. 2017. DOI: https://doi.org/10.24280/ape.v2i5.196

SEVERO, R. G.; SAN SEGUNDO, M. A. C. \#OCUPATUDORS - socialização política entre jovens estudantes nas ocupações de escolas no Rio Grande do Sul. ETD - Educação Temática Digital, Campinas, v. 19, n. 1, p. 73-98, jan./mar. 2017. DOI: https://doi.org/10.20396/etd.v19i1.8647792

SEVERO, R. G.; SAN SEGUNDO, M. A. C. Repensando o currículo a partir da ocupação de escolas. Práxis Educativa, Ponta Grossa, Ahead of Print, v. 14, n. 3, p. 1-17, set./dez. 2019.

SPOSITO, M. P. Algumas hipóteses sobre as relações entre movimentos sociais, juventude e educação. Revista Brasileira de Educação, Rio de Janeiro, n. 13, p. 73-94, jan./abr. 2000.

SPOSITO, M. P.; TARÁBOLA, F. de S. Entre luzes e sobras: o passado imediato e o futuro possível da pesquisa em juventude no Brasil. Revista Brasileira de Educação, Rio de Janeiro, v. 22, n. 71, p. 1-25, out. 2017. DOI: http://dx.doi.org/10.1590/s1413-24782017227146

THOMPSON, E. P. A miséria da teoria ou um planetário de erros: uma crítica ao pensamento de Althusser. Tradução de Waltensir Dutra. Rio de Janeiro: Zahar, 1981.

THOMPSON, E. P. Folclore, antropologia e história social. In: THOMPSON, E. P. As peculiaridades dos ingleses e outros artigos. Campinas: Editora Unicamp, 2001. p. 227-268.

Recebido em 12/03/2019

Versão corrigida recebida em 12/07/2019

Aceito em 13/07/2019

Publicado online em 18/07/2019

Práxis Educativa, Ponta Grossa, v. 14, n. 3, p. 1049-1065, set./dez. 2019 